\title{
Expert System Design for Sewage Treatment Plant
}

\author{
J. Bouza-Fernandez¹, G. Gonzalez-Filgueira ${ }^{1}$, \\ S. de las Heras Jimenez ${ }^{2}$ and D.Vazquez-Gonzalez ${ }^{1}$ \\ ${ }^{1}$ University of A Coruña, Ferrol, \\ ${ }^{2}$ Politechnical University of Catalunya, Terrassa, \\ Spain
}

\section{Introduction}

Nowadays the field of centralized control is linked to major production processes or industrial applications, where the flow of information allows optimizing the total production process. In the area of small to medium enterprises (SMEs) (Wang \& Kai-Yi, 2009), however it is still underdeveloped (Liao, 2009). Perhaps the reason is not the lack of capacity for the design or the cost of the technology, but the lack of vision and lack of skills, in addition to the benefits obtained with this type of automation. Added to this that the current diversity and technological capability allows to choose a wide range of both technical and economic possibilities. As a result, it is possible to select the technology in order to balance the binomial needs-costs.

In this line shows an application of centralized control, that is linked to a sewage treatment plant (Jiayu \& Linan, 2009; Zhu \& Liu, 2008) for the timber industry (Fig. 1), as a solution that not only reduces costs in human resources, but also increases the reliability and safety of the process compared to plants that operate semi-automatically and even, with respect to distributed control systems. Thus, from a control element single it is possible to manage, monitor and supervise, in real time, the whole system.

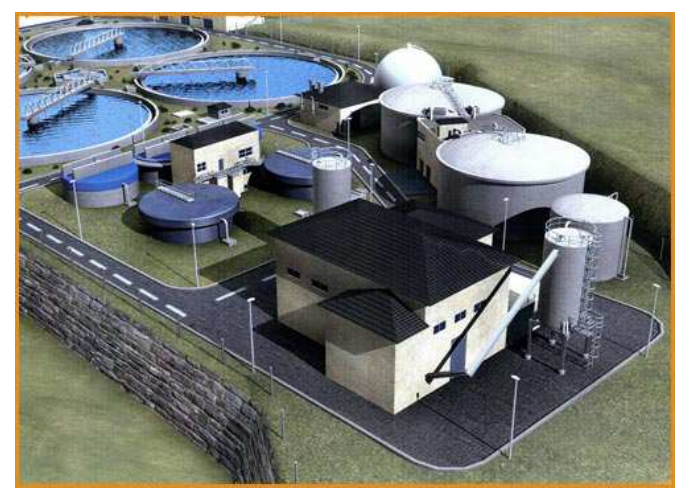

Fig. 1. Sewage Treatment Plant 
Despite that there are not known major applications of expert systems in sewage treatment, there are many attempts to apply knowledge-based systems in this area (Mikosz, 2001). However, these experts systems are not be able to maintain a continuous control of the plant, with data gathered through the on-line sensors.

The following flow chart (Fig. 2) shows the design procedure used in this project.

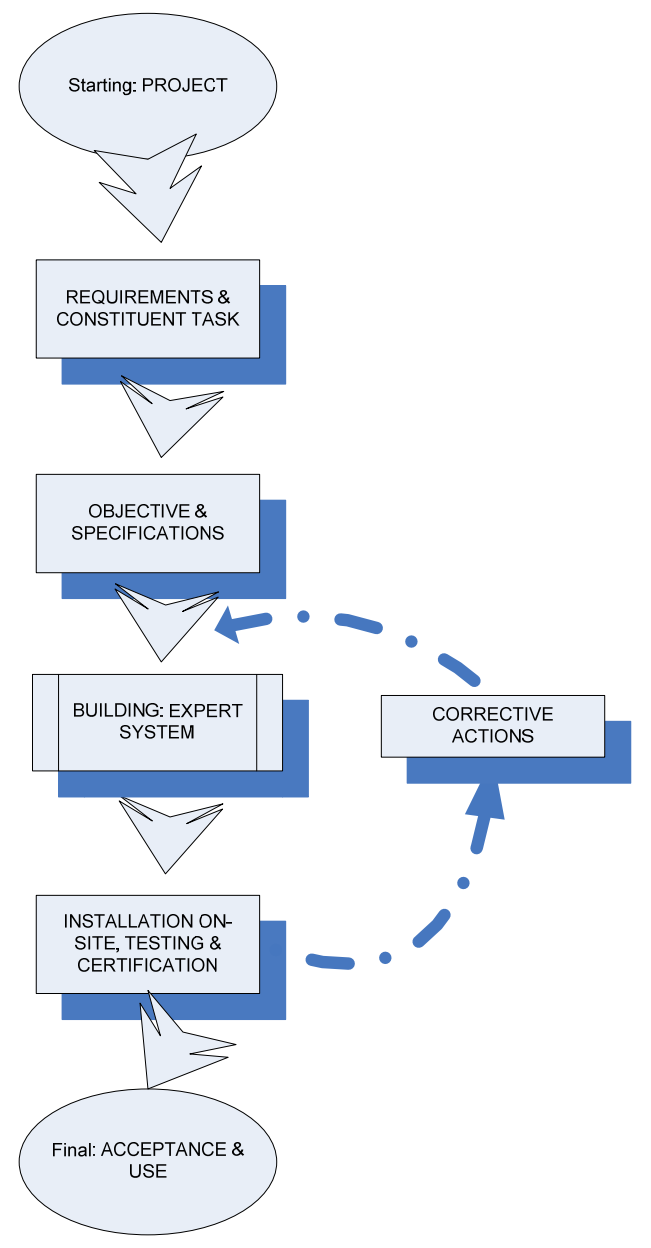

Fig. 2. Flow chart of design procedure

As far as the first phase, and starting point for this project, is concerned to a sewage plant for the Wood Products Industry which operates semiautomatic mode and with permanent presence of several operators to carry out the monitoring and supervision of the installation has been chosen. The system proposes that it should be possible to reduce the human presence to a single operator from a single point of control and that may be simultaneous with other plant processes. In addition to synchronize the various processes of the plant in 
order to improve the efficiency of the system, which affect the costs of production and levels of quality obtained in the purification process. Moreover, it is vital to minimize "human error" providing the operator with accurate and timely information accompanied by a set of records and alarms. This will increase the security of the system, and therefore, also, it will avoid any possible risk of environmental contamination.

This chapter discusses the relevant aspects for building an expert system that reaches the above requirements (Bouza-Fernandez, 2012). With regard to solve this problem of control such as application of the fuzzy logic (Kang, Yan-min \& Guo-chuan, 2009), it is thought that was not appropriate for two reasons:

1. First, this manufacturing process is correctly defined with level 2 GRAFCET and its non-linear structure is properly resolved with the monitoring and supervision of $\mathrm{Ph}$ and temperature magnitudes by means of the interface human machine (HMI) design, without the need to develop complex mathematical models.

2. And second, selecting the technology solution in order to balance the binomial needscosts, is an overriding aspect to comply with requirements demanded by customers. Day-to-day routine that designers must face, is "to develop the best solution in the shortest time and at the lowest cost".

Day-to-day routine that designers must face, is to develop the best solution in the shortest time and at the lowest cost. Although that aspects of installation and starting on site are not discussed in this document, if it is necessary to highlight its importance to carry out the project successfully. It must be said that these functions must be realized by qualified personnel in compliance with the guidelines of designer and respecting all safety rules. A complete verification of the operation and its safety will be done in this phase of the project, too. And the results will be contrasted with the specifications and tests carried out on the phase of building. If necessary, the pertinent corrections are made. In addition to this verification made by the Builder or Designer, usually another inspection is carried out by certification bodies or insurance companies.

A common factor of all the stages defined in this structure is that they suppose an evolution "from start to finish", that is to say, the concept of reference is described previously with approximation and later, it's perfected little by little and established of precise form. This structure allows a breakdown of the project in economic costs in their different stages, something fundamental for his acceptance and development. In this way, it is possible to minimize the risks inherent in his building, use, time and costs.

\section{Objective and specifications}

Following the flow chart design process described in Fig. 2, the objective and the specification of the system are defined in this section.

The objective of the control system is to improve efficiency and quality of the whole process of purification in two aspects:

a. On the one hand it involves a study of the process restructuring it or modifying those steps or elements deemed inefficient. 
b. In the other hand it provides continuous monitoring of sewage treatment. Also displays historical process data and manage the process notices provided by the system. This not only allows real time monitoring of the plant but also to make predictions or future prospects.

There is a relationship between the different elements of the control system SCADA and the work they do within the system. With these automated systems achieve optimize sewage treatment with comparison of actual and theoretical graphics. Modification of the existing situation assumptions are made and are valued, quantifying their effects to the objectives set. Therefore, the objective of operation of the plant is granted.

From a technological perspective, the following requirements for the development of the system control have been established:

a. Take advantage of, where possible, equipment and processes of the plant that is the object of this study.

b. The control system must govern all elements of the wastewater treatment plant performance, and monitor its proper functioning.

c. A program must be available for their daily operations and for emergencies and maintenance.

d. Provide clear and detailed system status, based on records and alarms, to facilitate human decisions making, if were necessary.

On the basis of these requirements, and prioritizing the relation cost-versatility, for the implementation of the system the following were chosen:

a. A series PLC Siemens S7-200 control system [SIMATIC, 1999; Siemens, 1998, 2000].

b. "WinCC Flexible SCADA" Siemens Software to design and monitor the HumanMachine Interface [Siemens, 2005](Penin, 2006). Fig. 3 shows a scheme of blocks of this system.

c. Re-using of existing equipment when it not minimizes the requirements for the control system. Elements strictly necessary are added for increasing the efficiency of the system.

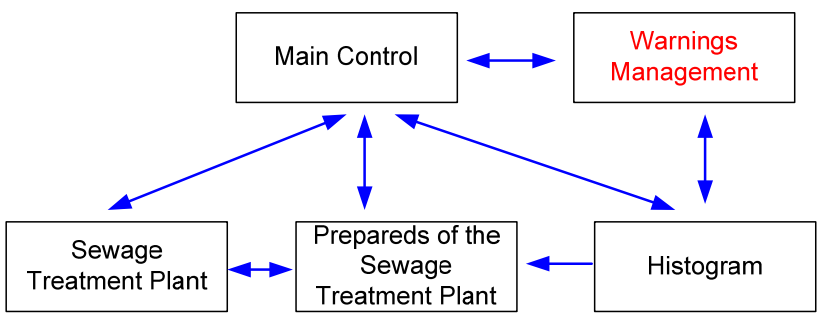

Fig. 3. Human-machine interface

\section{Building an expert system}

To design an automated system and its control for process, main part of this project, the procedure used is defined in Fig. 4. 


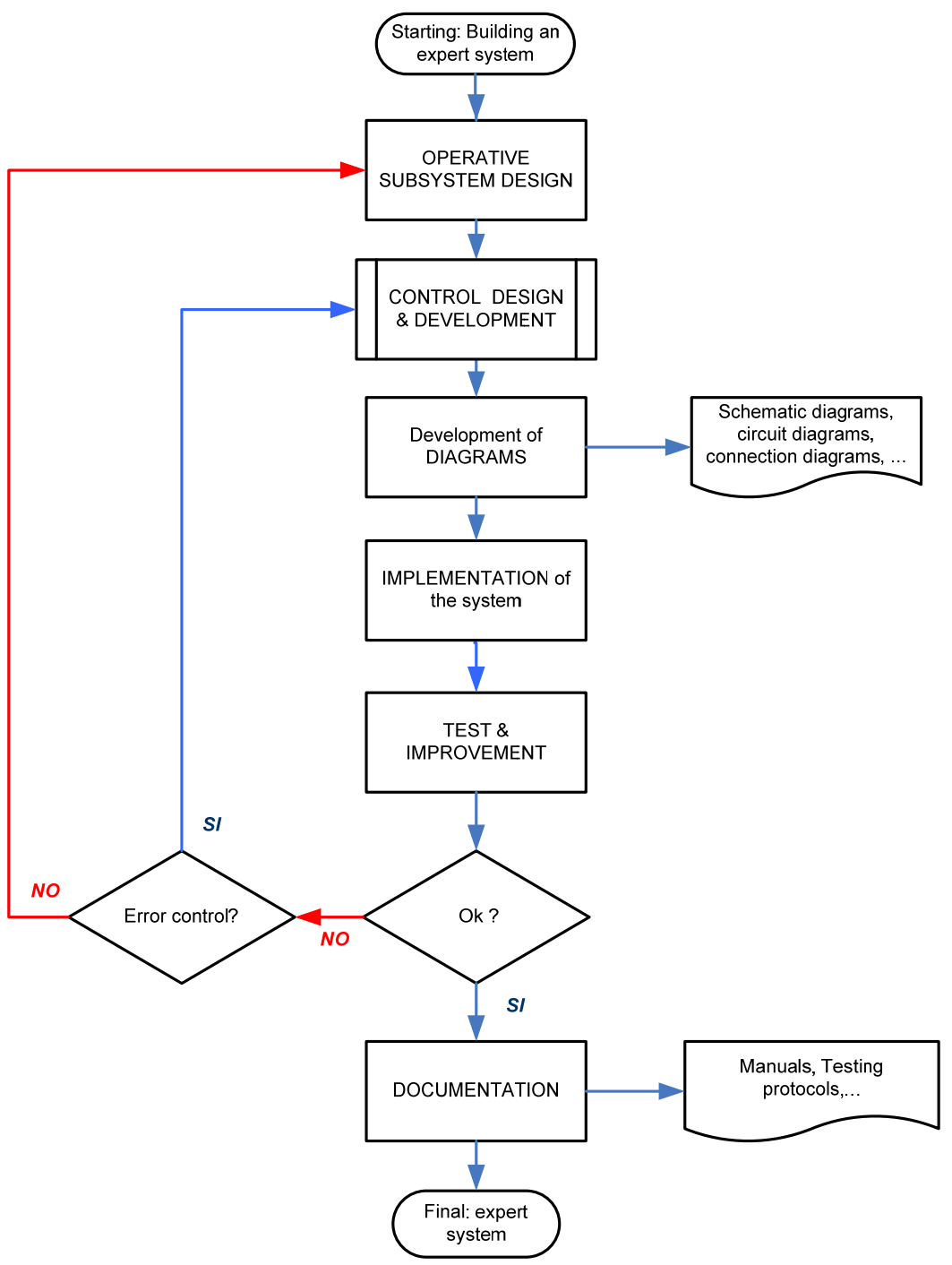

Fig. 4. Procedure for building an expert system

With reference to the development of the operative part of the system, it is necessary to do two basic aspects:

1. Description plant and process control.

2. Selection and sizing of components

As to the first point, the process of purification consists of the following processes: Filtering, elimination of the colloids through the process physical-chemical clotting and flocculation, treatment to regulate the $\mathrm{Ph}$ of the water, biological treatment and finally, decanting and 
sludge extraction. In Fig. 5 is shown a sewage treatment plant scheme where have place these processes.

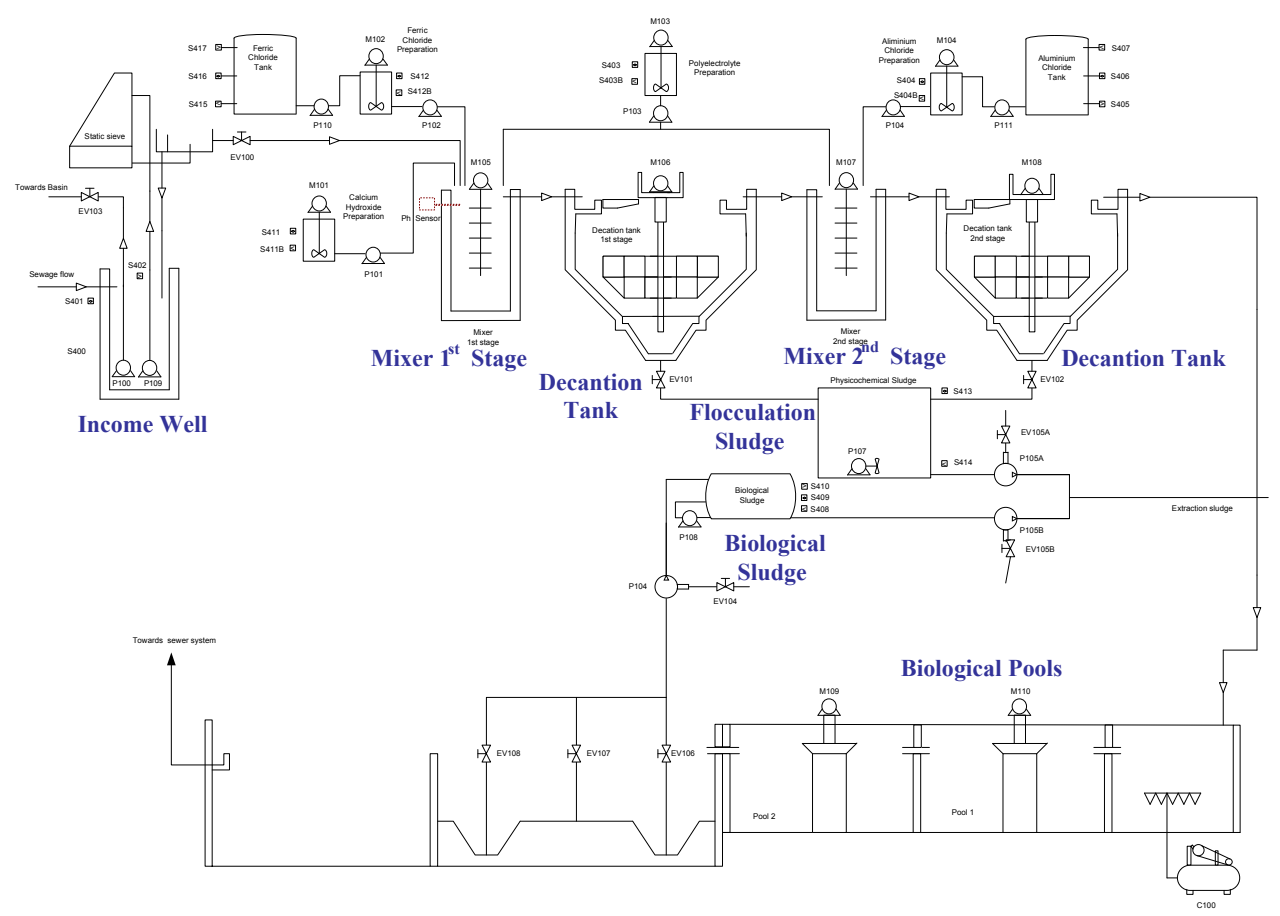

Fig. 5. Sewage Treatment Plant Scheme

The control system must govern all elements of performance of the sewage treatment Plant, and monitor its proper functioning. Moreover, it has to have a program for its daily operations and emergencies. All this accompanied by an information system supported by records and alarms to facilitate human decisions making, if were necessary. The control system may operate automatically according to operating programs daily and/or manually in case of emergency or tuning on.

Normally, in each of the control processes in a plant a programmable automation model is chosen. The process used here is continuous. Due to need for an algorithm as open as possible, in order to be able to work in different PLC's, depending on the needs of clients, and the capacities of the system, it has opted for a program in language of contacts that allow to be implemented in any PLC of the market. There is a cycle of working with seven processes that operate simultaneously or selectively. The activation of each of the processes will depend on the necessity to activate the process in question (Lira et al., 2003). The processes of the system are following:

- Process 1: "Water filling process".

- Process 2: "Process of polyelectrolyte preparation":

- Process 3 "Process of calcium hydroxide preparation"..

- Process 4: "Process of Ferric Chloride Preparation".. 
- Process 5: "Process of Aluminium chloride preparation".

- Process 6. "Process of physical-chemical sludge removal".

- Process 7: "Biological sludge Extraction Process".

- Process 8: "The emergency stop".

The water to be treated is stored in a basin. The purification process starts when the water enters the storage basin at the entrance well, in the well there is a pump that constantly circulates the water towards a static sieve which takes care of the solid waste. Once the water from the entrance well reaches the work level, it is directed to the mixer of the first stage.

In the mixers of the $1^{\text {st }}$ and $2^{\text {nd }}$ stage a variety of preparations will be added to water: ferric chloride, poly-electrolyte and aluminium chloride, to decant the water pollutants by coagulation and flocculation (process where colloids come out of suspension in the form of floc or flakes), in a solid waste called flocs. In order that this process takes place under optimum conditions of $\mathrm{pH}$, calcium hydroxide will be added at the $1^{\text {st }}$ stage. A motor will be continuously working throughout the process for mixing the different chemicals preparations to water. The waste water treated with these agents will be moved to some decanters in where the solid remains of the process, or flocs, will collect and will be stored in a deposit for that purpose. And the cycle of waste water treatment by biological treatment in pools will continue.

In the pools, the "biological treatment", it is made by the growth of a bacterial flora that eats dirt. The Ph level in the pools should not be very high because but bacteria responsible for the purification will not carry out its work correctly as it will protect itself due to the high $\mathrm{Ph}$ level. There is also in these pools a flow of sludge, which is removed in proportion to the water flow in it. In this way the excess of bacterial population is removed and recycled at the same time, which in turn maintains its capacity for purification. To maintain a level of oxygenation appropriate in the pools, air is injected, producing a bubbling of air from the bottom together with the action of some ventilators.

Both the sludge from the decanters and sludge extracted (Lindberg, 1997) from the pools of biological treatment will be removed to some tanks. In these tanks will be working some motors to prevent it from solidifying. To remove the sludge from the tanks will be used some pumps operated by some air motors, taking advantage of the air installation that exists to inject air into the pools.

In the second point for the selection and sizing of components, a deep knowledge of technology is needed. Diminishing the importance of this fact may bring irreparable losses in addition to endanger human lives. In their technical catalogues and software some manufacturers print the phrase "Failure or improper selection or improper use of the products and/or systems described herein or related items can cause death, personal injury and property damage". Depending on the engineer's previous experience the information and assistance required from manufacturers may vary considerably.

With the description of these two aspects, what has been tried to highlight is the need to consider many other factors, besides cost and technical performance when attempting to choose a make or type of system components. 
As for the second phase, "Control Design and development", develops the functional and operational aspects of the expert system and will be dealt with in depth in the next section. The estimate of the same ones, in programmable controller, option chosen in this project, is achieved frequently using a complex mathematical model or control algorithm. Obviously, the 'programmable' attribute increases the potential and the flexibility that has the designer but in contrast increases the complexity, the number of possible solutions and the time spent. Because of this there is a need to define procedures that save time and complexity, and that allow to obtain the optimum solution.

In phase 3, schematic diagrams and circuit diagrams will be made, which are particularly important to build the system and subsequently for realizing the installation and maintenance on site. These diagrams reflect the composition of the built system and will include all units of measurement, technical data of elements and their reference numbers.

For the phase 4, implementation of the control system, it will be necessary know specifications and principles of functioning of control elements used, that will be fundamental for their implementation.

In phase 5, 'Test \& Improvement', is to compare the expert system built with the initial requirements and the specification. This complete control of their functioning and operating mode must be made prior to its installation on site.

And last, but not least important, the documentation is an essential prerequisite to facilitate installation, final preparation and maintenance of the designed system. The documentation of the individual phases, including control programs should be available so on paper as on digital media. It goes without saying that the real state of the built expert system must coincide with the documentation.

\section{Control development and design}

The control system must govern all elements of performance of the sewage treatment Plant, and monitor its proper functioning. Moreover, it has to have a program for its daily operations and emergencies. All this accompanied by an information system supported by records and alarms to facilitate human decisions making, if were necessary. The control system may operate automatically according to operating programs daily and/or manually in case of emergency or tuning on. To design and develop the control for process, the following procedure has been established in Fig. 6. In this procedure, first all input variables that are to do with the control will be identified. And its constitution and behaviour will be scrutinised, as well as the margins of tolerance defined by the specification of the system. This allows to not only set the input parameters that will have to work with to solve the control algorithm but also to choose the appropriate control type: command or feedback control.

Normally, in each of the control processes in a plant we choose a programmable automation model. The process used here is continuous. The process involved in water waste removal can be separated into in different stages that must happen sequentially and correctly. Once the plant specifications have been laid down we continue to programme the plant design, a descending design "top-down" is used. Due to need for an algorithm as open as possible, in order to be able to work in different PLC's, depending on the needs of clients and the capacities of the system. The algorithm is implemented according to the Grafcet of the second level, Fig. 7, and the system requirements listed above. 


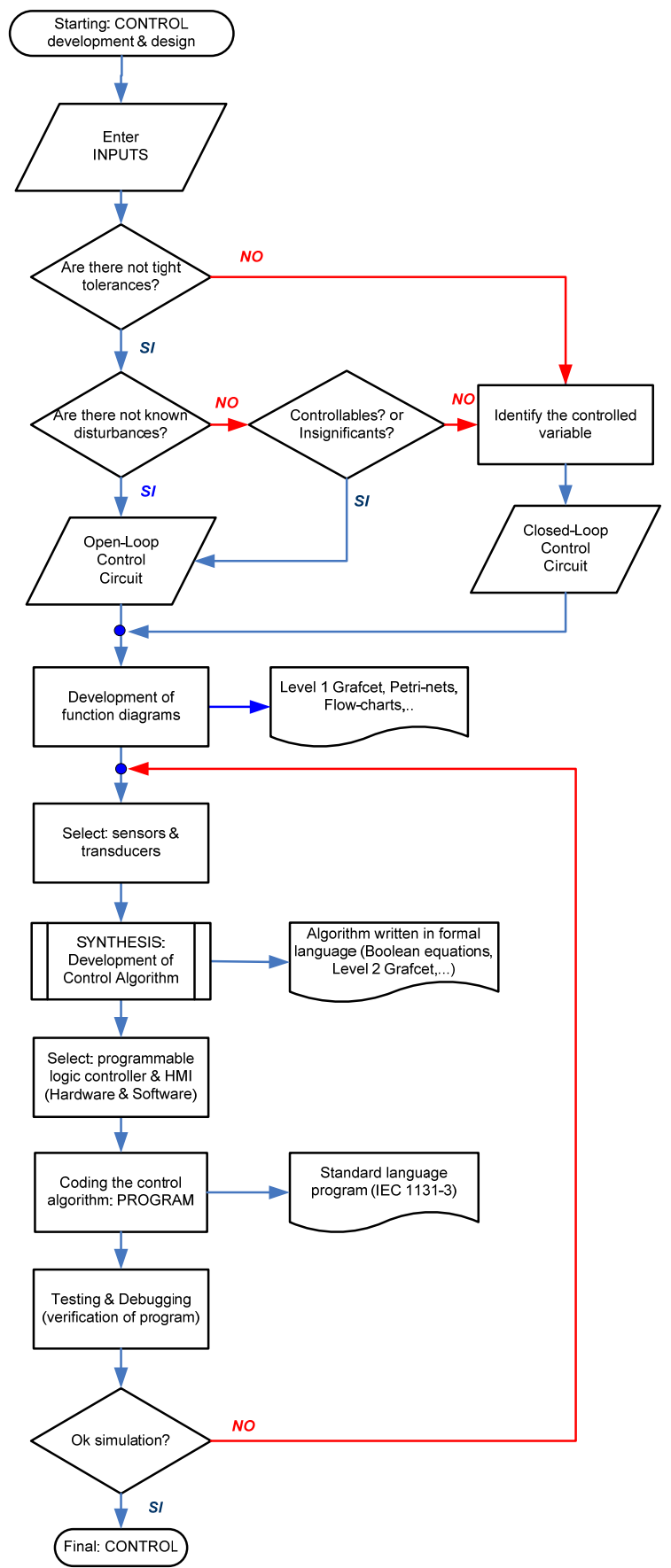

Fig. 6. Procedure for design and development of process control 


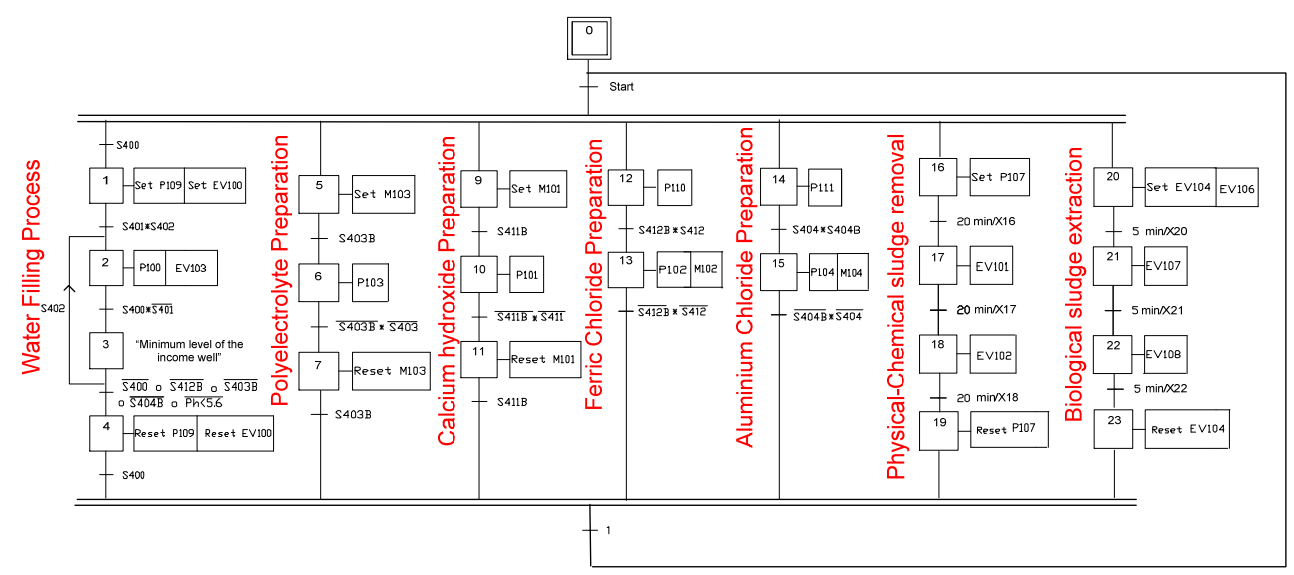

Fig. 7. Level 2 GRAFCET

The Table I and the Table II contain the description of input and output variables respectively used in the program. The analysis of GRAFCET of the second level, that represents the flow diagram of the states of the process, concluded that there is a cycle of working with seven processes that operate simultaneously or selectively. The activation of each of the processes will depend on the necessity to activate the process in question (Lira et al., 2003). The processes of the system are following:

a. Branch 1: "Water filling process". It starts with the "starting up" of the system and when the sensor S400, minimum level of water in the entrance well, is activated. Under these circumstances the pump P109 will start which will circulate water from entrance well through the static sieve. Then it will open the valve EV100 that will allow the passage of water to $1^{\text {st }}$ stage mixer. When sensors S401, due to work level, and S402, due to maximum level of water, are activated in the well, it will launch the P100 pump and will open the EV103 valve to discharge excess water from the entrance well towards the pool. This latter process will stop when the water in the well reaches the minimum level. The activation of the P109 pump and of the EV100 valve that cause water to flow into the other stages, will be cancelled if any of the sensors of minimum level of the tanks of preparation are activated (ferric chloride or polyelectrolyte or aluminium chloride) or if the Ph level in the "Mixer for $1^{\text {st }}$ stage" is less than 5.6.

b. Branch 2: "Process of polyelectrolyte preparation": When activating the "Start-up", this starts the M103 motor that turns the contents of the tank that contains the polyelectrolyte preparation and the water to mix. If the S403B sensor is activated, which is the minimum level of the deposit, the P103 pump, will be activated and this is responsible for providing the preparation to the mixer 1st and 2nd stage. If minimum level sensor is disabled or the emergency stop is activated, the motor of remover in the tank of prepared of polyelectrolyte will stop.

c. Branch 3 "Process of calcium hydroxide preparation". When activating the "Startup", it starts the motor M101 responsible for mixing the calcium hydroxide prepared solution in the preparation tank. If the S411B sensor minimum level of preparation is activated, the P101 pump which provides the mixture of the $1^{\text {st }}$ stage will be activated. Disabling the minimum level sensor of preparation (S411B) or activating the emergency stop will stop the M101 motor. 


\begin{tabular}{|c|c|}
\hline Inputs & Function: Level Sensors \\
\hline $\mathrm{I} 0.0$ & Minimum level. Income Well (S400) \\
\hline $\mathrm{I} 0.1$ & Reference level. Income Well (S401) \\
\hline $\mathrm{I} 0.2$ & Maximum level. Income Well (S402) \\
\hline $\mathrm{I} 0.3$ & Maximum level. Ferric Chloride Preparation (S412) \\
\hline $\mathrm{I} 0.4$ & Minimum level. Ferric Chloride Tank ( S415) \\
\hline $\mathrm{I} 0.5$ & Reference level. Ferric Chloride Tank (S416) \\
\hline $\mathrm{I} 0.6$ & Maximum level. Ferric Chloride Tank (S417). \\
\hline $\mathrm{I} 0.7$ & Maximum level. Calcium Hydroxide Preparation (S411). \\
\hline I1.0 & Maximum level. Polyelectrolyte Preparation (S403). \\
\hline I1.1 & Maximum level. Aluminium Chloride Preparation (S404) \\
\hline I1.2 & Minimum level. Aluminium Chloride Tank (S405). \\
\hline I1.3 & Reference level. Aluminium Chloride Tank (S406). \\
\hline I1.4 & Maximum level. Aluminium Chloride Tank (S407). \\
\hline I1.5 & Minimum level. Biological Sludge Tank (S408) \\
\hline I1.6 & Reference level. Biological Sludge Tank (S409). \\
\hline I1.7 & Maximum level. Biological Sludge Tank (S410). \\
\hline $\mathrm{I} 2.0$ & Maximum level. Physicochemical Sludge Tank(S413). \\
\hline $\mathrm{I} 2.1$ & Minimum level. Physicochemical Sludge Tank (S414). \\
\hline $\mathrm{I} 2.2$ & Minimum level. Ferric Chloride Preparation (S412B). \\
\hline I2.3 & Minimum level. Aluminium Chloride Preparation (S404B) \\
\hline I2.4 & Minimum level. Calcium Hydroxide Preparation (S411B). \\
\hline $\mathrm{I} 2.5$ & Minimum level. Polyelectrolyte Preparation (S403B). \\
\hline Inputs & Function: Analog Sensors \\
\hline AIW0 & Ph value. Mixer 1st Stage \\
\hline AIW2 & Temperature. Mixer 1st Stage \\
\hline Inputs & Function: Memory \\
\hline M0.0 & Start \\
\hline M0.1 & Emergency Shutdown \\
\hline M0.2 & Reset of the System \\
\hline M0.3 & Empty income Well \\
\hline M1.0 & Emergency Shutdown Light \\
\hline M1.1 & Set/Reset of EV101 \&EV102. Drain valves of Decantion Tanks (1st \& 2st stage) \\
\hline M1.2 & Set/Reset EV105A. \\
\hline M1.3 & Set/Reset EV105B. \\
\hline
\end{tabular}

Table 1. Program inputs 


\begin{tabular}{|c|c|}
\hline Outputs & Function \\
\hline Q0.0 & Recirculating Pump towards Basin(P100) \\
\hline Q0.1 & Recirculating Electro-valve towards Basin (EV103) \\
\hline Q0.2 & Pump. Income Well (P109). \\
\hline Q0.3 & Electro-valve. 1st Stage Mixing (EV100). \\
\hline Q0.4 & Pump. Calcium Hydroxide Preparation (P101) \\
\hline Q0.5 & Mixing Motor .Calcium Hydroxide Preparation (M101). \\
\hline Q0.6 & Pump. Ferric Chloride Preparation (P102). \\
\hline Q0.7 & Pump. Ferric Chloride Tank (P110). \\
\hline Q1.0 & Mixing Motor. Ferric Chloride Preparation (M102) \\
\hline Q1.1 & Mixing Motor. 1st Stage (M105) \\
\hline Q1.2 & Mixing Motor. 1st Stage Decantion Tank (M106) \\
\hline Q1.3 & Sludge Extraction Electro-valve. 1st Stage Decantion Tank (EV101) \\
\hline Q1.4 & Mixing Motor. 2nd Stage (M107) \\
\hline Q1.5 & Mixing Motor. 2nd Stage Decantion Tank (M108) \\
\hline Q1.6 & Sludge Extraction Electro-valve. 2nd Stage Decantion Tank (EV102) \\
\hline Q1.7 & Mixing Motor. Polyelectrolyte Preparation (M103) \\
\hline Q2.0 & Pump. Polyelectrolyte Preparation (P103) \\
\hline Q2.1 & Pump. Aluminium Chloride Tank (P111) \\
\hline Q2.2 & Pump. Aluminium Chloride Preparation (P104). \\
\hline Q2.3 & Mixing Motor. Aluminium Chloride (M104). \\
\hline Q2.4 & Submergible Pump. Physicochemical Sludge Tank (P107). \\
\hline Q2.5 & Recirculating Pump. Biological Sludge Tank (P108). \\
\hline Q2.6 & $\begin{array}{l}\text { Electro-valve for control of Extraction Pump. Physicochemical Sludge } \\
\text { (EV105A) }\end{array}$ \\
\hline Q2.7 & Electro-valve for control of Extraction Pump. Biological Sludge (EV105B). \\
\hline Q3.0 & Electro-valve for control of Extraction Pump. Pools Sludge (EV104). \\
\hline Q3.1 & Extraction Electro-valve. Pools Sludge (EV106). \\
\hline Q3.2 & Extraction Electro-valve. Pools Sludge (EV107). \\
\hline Q3.3 & Extraction Electro-valve. Pools Sludge (EV108) \\
\hline Q3.4 & Air Injection Motor. Pool 2 (M109). \\
\hline Q3.5 & Air Injection Motor. Pool 1 (M110). \\
\hline Q3.6 & Air Compressor (C100). \\
\hline
\end{tabular}

Table 2. Program outputs

d. Branch 4: "Process of Ferric Chloride Preparation". With the system in motion the P110 pump that supplies ferric chloride to preparation tank to reach the maximum level 
detected by $\mathrm{S} 412$ sensor. Then in turns starts the M102 motor, responsible for removing the preparation, and the P102 pump that supplies the preparation in $1^{\text {st }}$ stage mixer. Disabling the prepared minimum level S412B sensor or activating emergency stop, the M102 motor and P102 pump will stop.

e. Branch 5: "Process of Aluminium chloride preparation". It is similar to the branch 4, by changing the designation of sensors and actuators. Its output is the mixer stage 2, instead of stage 1. With the system in motion, the P111 pump starts which supplies aluminium chloride preparation in the deposit up to the maximum level detected by S404. Then it will launch the M104 engine, responsible for mixing the preparation, and the P104 pump that supplies the preparation in 2nd stage mixer. Disabling the preparation minimum level S404B sensor or activating emergency stop, will stop the M104 motor and P104 pump.

f. Branch 6. "Process of physical-chemical sludge removal": When activated the "Startup" in the SCADA panel, the submersible P107 mixer is put into operation that ensures the physical-chemical sludge does not solidify. Twenty minutes after the process starts, the EV101 opens to extract the sludge from decanter of 1st stage for another 20 minutes. Immediately the EV101 closes and the EV102 opens to remove, in this case, the sludge from the decanter of $2^{\text {nd }}$ stage for another 20 minutes. This cycle is repeated continuously unless the process is stopped.

g. Branch 7: "Biological sludge Extraction Process". When "Startup" on SCADA panel is activated, it starts the EV104 valve that operates the P104 pump, responsible for the extraction of biological sludge, and opens EV106 valve that connects the aspiration of the pump. After 5 minutes, the EV106 closes and the EV107 and EV108 valves opens for another 5 minutes each alternately connecting to the pump suction.

With regards to "the emergency stop": If emergency stop in the SCADA is activated the entire installation will stop and remain locked until reset is activated. The activating the emergency stop paralyzes all motors and pumps and puts the valves in a stand by position, leaving different system processes to be automatically locked until the system is rearmed.

This description Grafcet is translated and converted into Boolean equations for development the control program for this process. In order to codify the program, the Boolean equations are converted ladder diagrams (Fig. 8) to create logic networks but using certain techniques to express and identify the sequence logic equations that control the system outputs. Besides, ladder diagrams allow to be implemented in any PLC of the market.

Finally, the expert system specifications chosen for this design are:

a. SCADA System:

Display and management of real time processing.

Displays alarms and warnings.

Display alarm history, and notices.

Information about the protocol for each alarm or warning activated.

Two way communication with S7 PLC.

b. The PLC Program:

Include functions and sequences of the plant standards.

Must establish procedures for cases of failure or emergency. With warning signs and alarms well marked.

Structured programming to facilitate any changes or upgrades. 
Allow two-way communication with the SCADA system (Cao, 2009; Tian et al., 2008). Reading and interpreting all types of signals: analogue or digital

Control and supervision of the actuators and field elements.

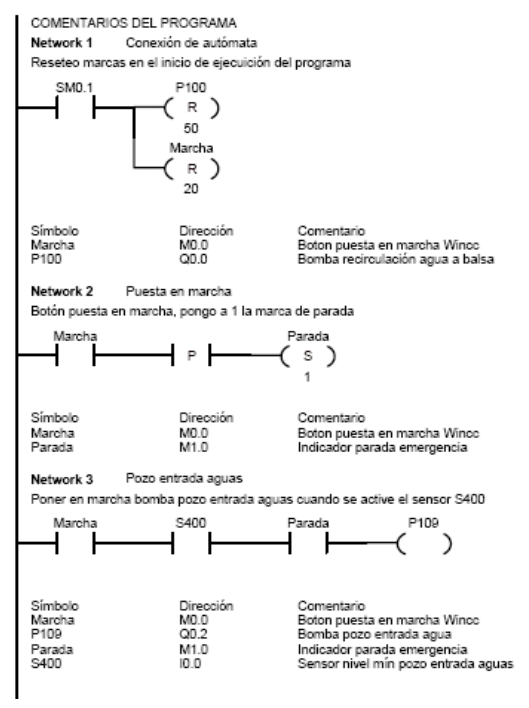

Fig. 8. Ladder diagrams

\section{Synthesis: Problem solution}

The design and development of the control program is of vital importance due to it constitutes the means for controlling the process. For the controller to carry out its intended task, a control program is necessary. The planning and design work for this process is complex. The following procedure, shown in Fig. 9, has been established in order that the program can be easily developed, verified and documented. An important part of this procedure is the division of programming tasks into two fundamental blocks: on the one hand to solve the sequential problem, on the other hand to implement safety (emergency stop, alerts,...) and operating modes (start conditions, reset, empty income well,...). The following Table 3 provides a good practice guide.

1. Plan your program on paper first " $80 \%$ of your time should be spent working out the program, and only $20 \%$ keying it in"

2. Keep documentation of all elements used in the program and add so comments as necessary.

3. Assume the program will find every error sequence possible, "design safety into it!"

4. Keep programs simple and readable. Comments would be helpful

5. Try sectional development and verifying if possible.

6. Analysis of operation program in situations where it is safe to do so and simulate failures.

Table 3. Good programming practice 
The sequential problem has been structured with definite sections dealing about specific areas of process. By adopting this approach, the programs developed are reliable and can be easily understood.

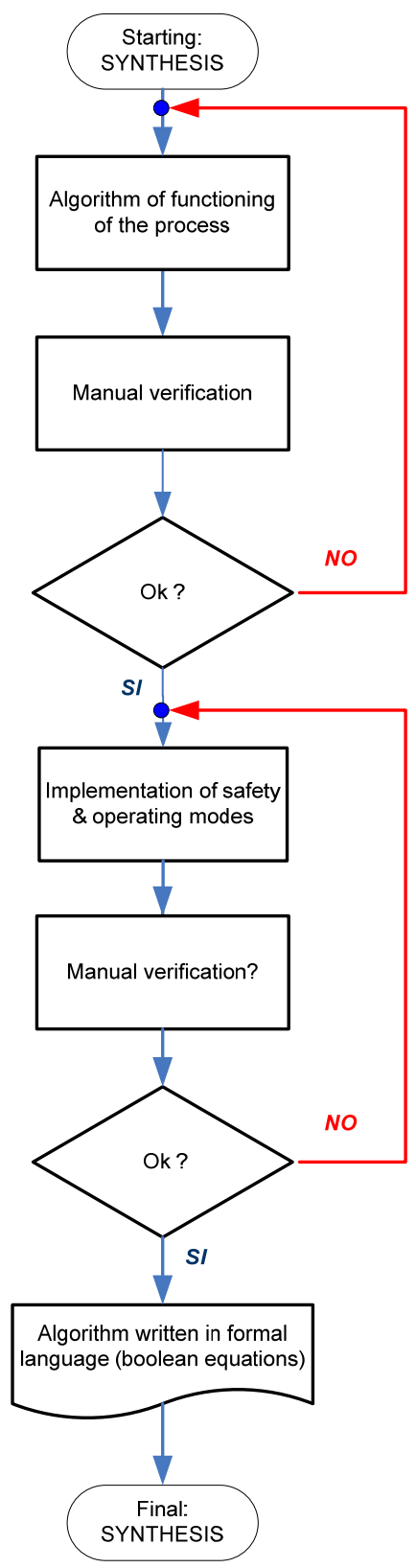

Fig. 9. Procedure for design and development of process control 
For example, one of the complicated aspects of the process is the need to control and maintain constant the $\mathrm{pH}$ and temperature of water coming from the entrance well. To take the measurement, two transducers are used that convert physical quantities, temperature and $\mathrm{pH}$, into two signals of intensity. This signal intensity, shown in Fig. 10, is received by the PLC via an analog module (EM235) that makes the conversion for its interpretation and comparison with the desired values and thus the corrective actions in the system are made. Thus, one of the calculations is the conditioning of the analog sensors. So the Ph transducer provides as output a variable current signal from 4 to $20 \mathrm{~mA}$ that reads analog module of the PLC and it becomes a 12-bit digital value. This value is stored in the analog input word,

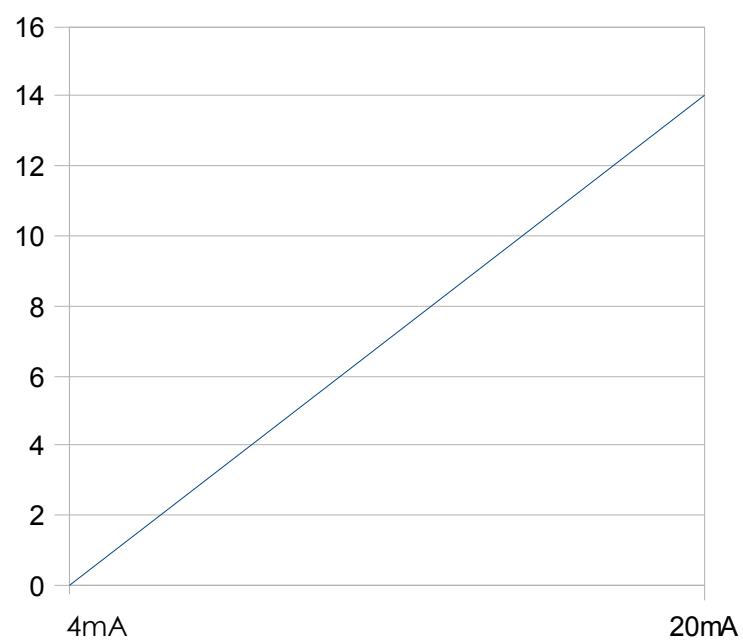

Fig. 10. Current's variation in function $\mathrm{Ph}$

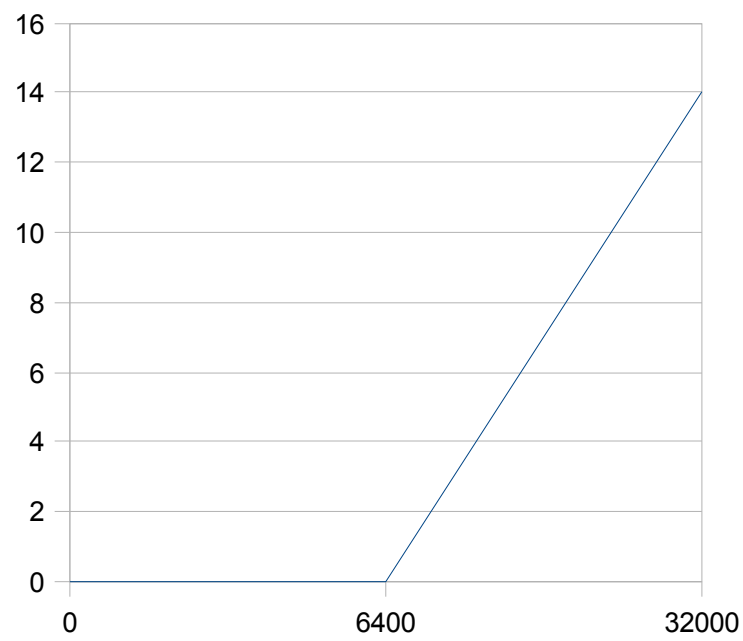

Fig. 11. Variation of AIW0 analog input in function Ph 
AIW0, and because of the signal has a unipolar format, your range will be between 6400 and 32000 as is shown in Fig. 11. Therefore it will be necessary to scale and standardize this variable to the actual range of $\mathrm{pH}$, from 0 to 14 .

Using the equation:

$$
\mathrm{y}-\mathrm{y}_{0}=\mathrm{m} \cdot\left(\mathrm{x}-\mathrm{x}_{0}\right)
$$

and solving for the values of the extremes, is obtained the slope of the line depending on the analog input value.

$$
\mathrm{m}=(14 / 25600)=0.0546 .10^{-3}
$$

So the equation to implement in the PLC program to know the real value of $\mathrm{Ph}$ is:

$$
\text { 14-Ph }=\mathrm{m} \text {. (3200-AIW0) }
$$

So for:

a. $\mathrm{Ph}=5 ; \mathrm{y} 0=9.71 \mathrm{~mA}=15543$ that is the value to compare in the PLC program as a minimum value of $\mathrm{Ph}$.

b. $\mathrm{Ph}=7 ; \mathrm{y} 0=12 \mathrm{~mA}=19200$, that is the value to compare in the PLC program the maximum value of $\mathrm{Ph}$.

c. $\mathrm{Ph}=5.8 ; \mathrm{y} 0=10.63 \mathrm{~mA}=17000$, that is the value to compare in the PLC program as a minimum value of $\mathrm{Ph}$.

\section{Implementation and results}

It has been initiated to implement an expert system in the total control of the process and has been complemented with a set of records and alarms. This has revealed in real time the operation state of the process, which it allows to carry out analysis functions, correct them and act appropriately. It has been developed a Supervisory Control Acquisition Data Analysis (SCADA) system that is structured in a main screen from that is obtained access to the other four: Sewage Treatment Plant, Prepared of the Sewage Treatment Plant, Warnings, and Histogram.

\subsection{Main screen}

The main screen, that is shown in Fig. 12, gives access to all screens. It allows handling the whole process: start, emergency stop, reset and empty the entrance well. It also displays the different states of the system in the box "System Status".

\subsection{Sewage treatment plant screen}

From the screen shown in Fig. 13 and Fig. 14 the overall process of purification of the sewage plant is monitored and controlled. One of the important aspects of the process is the need to control and maintain constant the $\mathrm{pH}$ and temperature of water coming from the entrance well. To take the measurement, two transducers are used that convert physical quantities, temperature and $\mathrm{pH}$, into two signals of intensity. The state of the system and the different processes are displayed, in addition of showing the levels of $\mathrm{pH}$ and temperature of the water in the entrance well. 


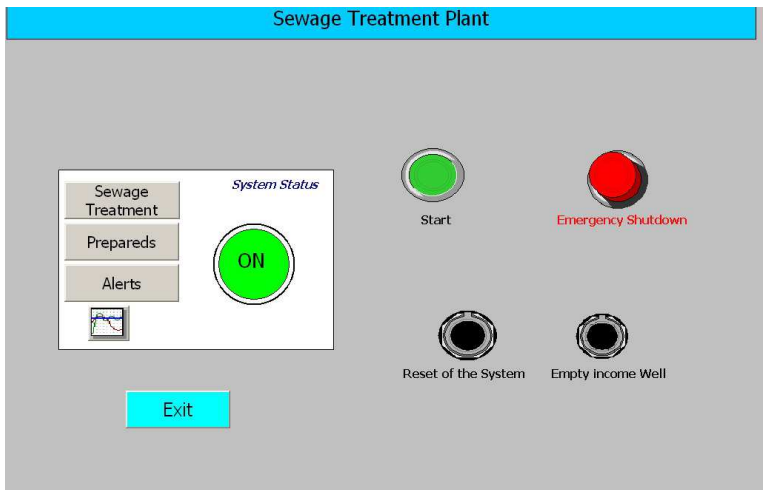

Fig. 12. Menu of Main Screen Sewage Treatment Plant

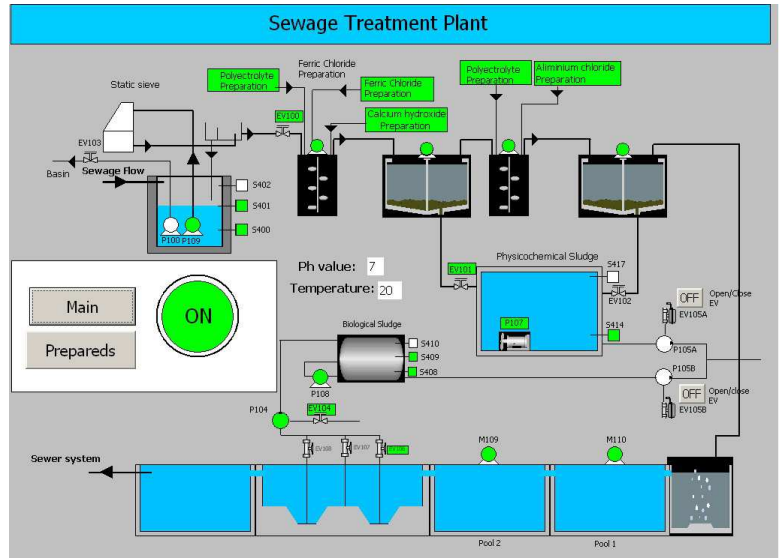

Fig. 13. Main Screen Sewage Treatment Plant in status operation normal

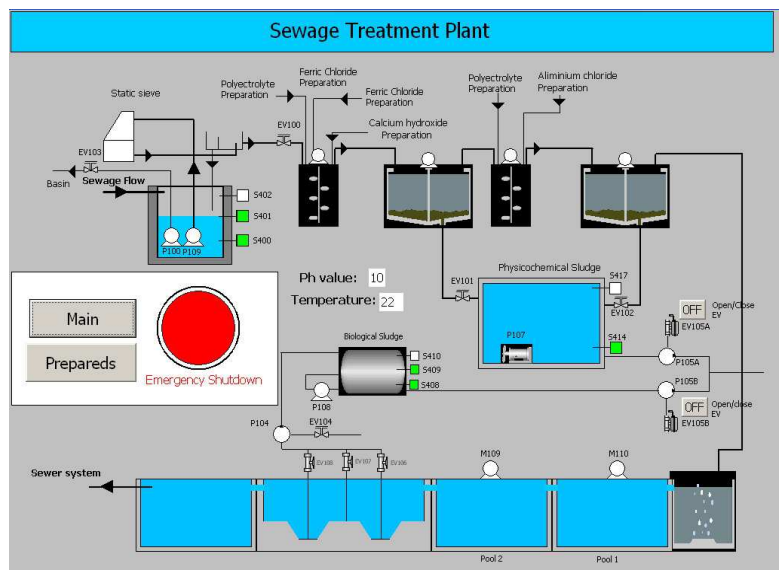

Fig. 14. Main Screen Sewage Treatment Plant. Powered emergency shutdown 


\subsection{Prepared of the sewage treatment plant screen}

This screen displays the different preparations which are going to add to water for physicalchemical treatment of flocculation and coagulation. Fig. 15 shows this treatment

Thus, from this screen is possible to control the levels of the different machines needed to perform the different functions in the purification process, such as the pumps and motors.

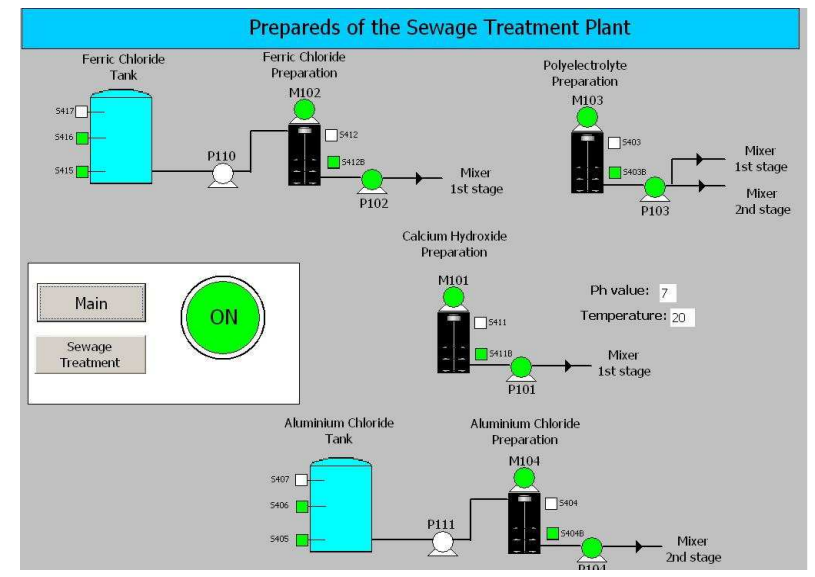

Fig. 15. Prepared of Sewage Treatment Plant Screen

\subsection{Warnings}

This screen displays warnings and system alarms set up. In both cases, shown in Fig. 16, apart from the source, reflects the date and time.

In the proposed control system, in addition to the specific warnings of the system HMI that reports the state of service, are defined the following:

a. Warnings Service. It reports irregularities in the service or in the process of the Sewage Treatment Plant, and the effects on the efficiency of the process. These warnings are automatically generated and are a necessary information for the operator in making decisions. For example, inadequate levels of temperature or $\mathrm{pH}$ will be referred to in messages to report this fact (see alert in Fig. 16).

b. Alarms. These show states of malfunction or danger in the process. These alarms require mandatory action by an operator after its recognition, and are usually accompanied by the shutdown of the system to remedy the problem (for example in Fig. 14 ). It is distinguished, in this project, among two types of alarms, according to the typology of signal: binary notices for level sensors in the different tanks, and announcements concerning the analogue temperature sensor and $\mathrm{pH}$ sensor, for which it has set an upper limit and lower one involving a failure or risk at the plant.

\subsection{Histogram screen}

Fig. 17 shows the two analogue variables, Ph level and temperature, depending on the time, when the system is on, and Fig. 18 shows when the system there is an emergency shutdown. 


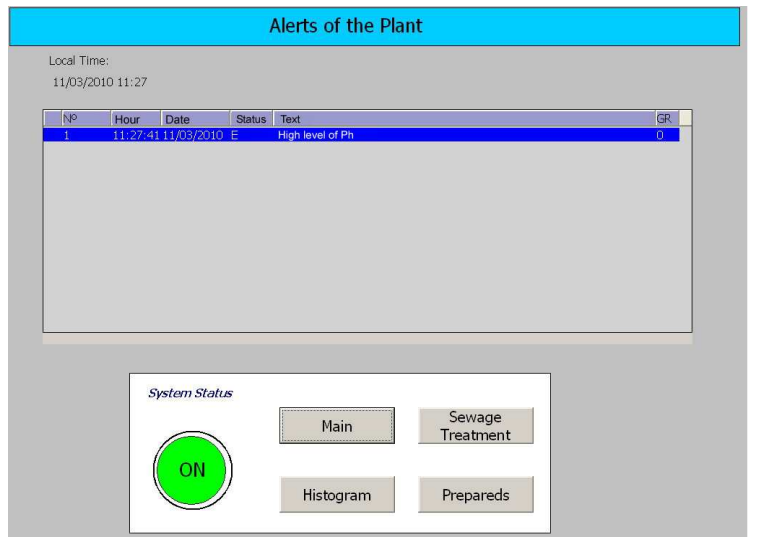

Fig. 16. Warnings Screen Sewage Treatment Plant

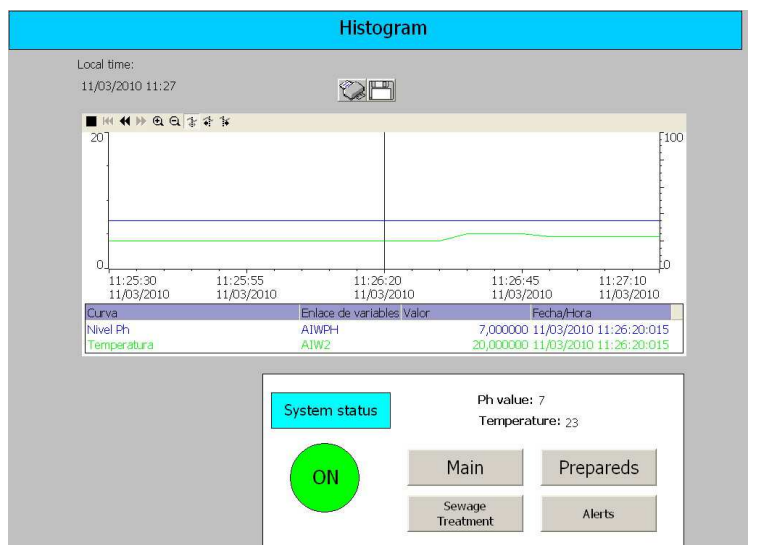

Fig. 17. Histogram Screen when the system is on

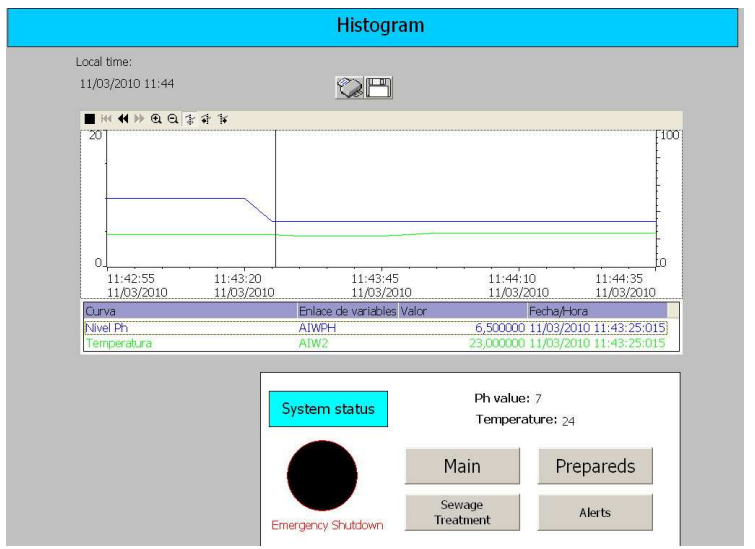

Fig. 18. Histogram Screen when the system is down 


\section{Conclusion}

This work has been carried out using a process of control, supervision and monitoring of a purification plant intended for the wood Industry. It has been initiated to implement an expert system in the total control of the process and has been complemented with a set of records and alarms. This has revealed in real time the operation state of the process, which allows us to carry out analysis functions, correct them and act appropriately.

The choice of a PLC as a control device, not only has guaranteed the interconnectivity and compatibility of the various equipments through interfaces and protocols, but also has also facilitated the interoperability with the used SCADA implementation. At the same time, there are advantages of allowing using industrial PLC, and especially in this project, it gives flexibility for future upgrades or modifications of the process. The WinCC SCADA with which has been developed the Human-Machine Interface ("HMI") of the system, in addition to its compatibility with the PLC, has helped reduce the processing times of the project due to its versatility and ease of programming.

The reduction of the presence in human staff to a single operator, is not detrimental to the operation of the installation, because the expert system proposed improves the quality of work of the operator and minimizes "human error". All this has an impact on increasing the security of the installation, and in short, prioritises environmental protection, the main objective of this process.

\section{References}

Bouza-Fernandez, J. (2012). “Development and optimization methodologies for the design and efficient implementation of electro-hidraulic and electro-pneumatic systems" Ph.D. dissertation, Dept. Naval and Oceanic Engineering, University of A Coruña, A Coruña, Spain, 2011.

Cao, L. (2009). Wireless mesh monitoring system for sewage treatment plant, Computing, Communication, Control, and Management, 2009. CCCM 2009. ISECS International Colloquium on, vol.4, no., pp.350-353, Sanya 8-9 Aug

Jiayu, K. , Linan, M. (2009). An expert system for anaerobic wastewater treatment process, Information and Automation, 2009. ICIA '09. International Conference on, pp.422-425, Zhuhai, Macau, 22-24 June

Kang S., Yan-min S., Guo-chuan F (2009). The Application of the Fuzzy Controller Based on PLC in Sewage Disposal System. 2009 International Conference on Artificial Intelligence and Computational Intelligence, pp.154-158. ISBN: 978-0-7695-3816-7/09. DOI 10.1109/ AICI.2009.403.

Liao, J.Q. (2009). Economic analysis on urban domestic sewage treatment, Computing, Communication, Control, and Management, 2009. CCCM 2009. ISECS International Colloquium on, vol.2, no., pp.334-339, Sanya, 8-9 Aug

Lindberg, C. F. (1997) Control and estimation strategies applied to the activated sludge process, Ph.D. dissertation, Uppsala University, Uppsala, Sweden

Lira, V.V. , da Rocha Neto, J.S., Barros, P.R. \& van Haandel, A.C. (2003). Automation of an anaerobic-aerobic wastewater treatment process, Instrumentation and Measurement, IEEE Transactions on, vol.52, no.3, pp. 909-915, June 
Mikosz, J. (2001) Application of expert systems in wastewater treatment: Wastewater sludge and solid waste management, Report No 9. M. Hopkowicz, B. Hultman, J. Kurbiel, E. Plaza (Editors), TRITA-AMI REPORT 3088, p. 137

Penin A.R., (2006) Sistemas SCADA. Marcombo S.A, Spain

Siemens, (1998). Autómata Programable S7-200, Configuración, instalación y Datos de la CPU, Ref.: 6ES7-398-8AA03-8DA0

Siemens, (2000). Manual de Programación. Software de Sistema para S7-200. Diseño de programas, Ref.: 6ES7-810-4CA04-8DA0

Siemens, (2005). Wincc. Manual de Configuración. Vol. 1, Ref.: 6AV6392-1CA05-0AB0

SIMATIC (1999) S7-200 Programmable Controller System Manual

Tian, J., Wu, H., Gao, M. (2008). Measurement and control system of sewage treatment based on wireless sensor networks", Industrial Technology, 2008. ICIT 2008. IEEE International Conference on, vol., no., pp.1-4. Chengdu 21-24 April

Wang, E.M.-Y.; Kai-Yi L.( 2009); A human factors improvement on supervisory alarms in wastewater treatment system, Industrial Engineering and Engineering Management, 2009. IEEEM '09. 16th International Conference on, vol., no., pp.618-621, Beijing, China, 21-23 Oct

Zhu Z., Liu, J. (2008). Remote monitoring system of urban sewage treatment based on Internet, Automation and Logistics, 2008. ICAL 2008. IEEE International Conference on, pp.1151-1155, Qingdao, 1-3 Sept 


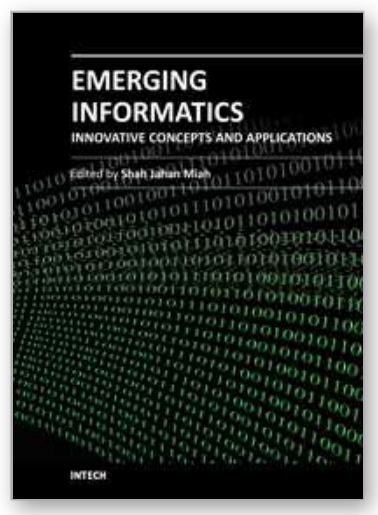

\author{
Emerging Informatics - Innovative Concepts and Applications \\ Edited by Prof. Shah Jahan Miah
}

ISBN 978-953-51-0514-5

Hard cover, 274 pages

Publisher InTech

Published online 20, April, 2012

Published in print edition April, 2012

The book on emerging informatics brings together the new concepts and applications that will help define and outline problem solving methods and features in designing business and human systems. It covers international aspects of information systems design in which many relevant technologies are introduced for the welfare of human and business systems. This initiative can be viewed as an emergent area of informatics that helps better conceptualise and design new world-class solutions. The book provides four flexible sections that accommodate total of fourteen chapters. The section specifies learning contexts in emerging fields. Each chapter presents a clear basis through the problem conception and its applicable technological solutions. I hope this will help further exploration of knowledge in the informatics discipline.

\title{
How to reference
}

In order to correctly reference this scholarly work, feel free to copy and paste the following:

J. Bouza-Fernandez, G. Gonzalez-Filgueira, S. de las Heras Jimenez and D.Vazquez-Gonzalez (2012). Expert System Design for Sewage Treatment Plant, Emerging Informatics - Innovative Concepts and Applications, Prof. Shah Jahan Miah (Ed.), ISBN: 978-953-51-0514-5, InTech, Available from:

http://www.intechopen.com/books/emerging-informatics-innovative-concepts-and-applications/expert-systemdesign-for-sewage-treatment-plant

\section{INTECH}

open science | open minds

\author{
InTech Europe \\ University Campus STeP Ri \\ Slavka Krautzeka 83/A \\ 51000 Rijeka, Croatia \\ Phone: +385 (51) 770447 \\ Fax: +385 (51) 686166 \\ www.intechopen.com
}

\author{
InTech China \\ Unit 405, Office Block, Hotel Equatorial Shanghai \\ No.65, Yan An Road (West), Shanghai, 200040, China \\ 中国上海市延安西路65号上海国际贵都大饭店办公楼 405 单元 \\ Phone: +86-21-62489820 \\ Fax: $+86-21-62489821$
}

